Europe have been affected by the changes in their countries' economies, the creation of multi-party political systems and broader changes in gender roles, while Sumbadze and Tarkhan-Mouravi provide an intergenerational analysis of values and lifestyles of young people in Georgia. The last three chapters reveal how particular social groups become 'socially excluded' in European societies. Research into the situation of lone young mothers in Italy (Ruspini) shows how inequality factors converge for those in 'anomolous' positions. For young unemployed people with multiple problems in the UK, structural disadvantages complicate their situation further (Parry) while Monro's unique study on trans-gender young people leads into an argument for a social system more tolerant of gender diversity.

Overall, the book will be a rich resource for those seeking to make sense of new evidence in the search for better understandings of the contemporary situation of youth in the expanded Europe and beyond. Better understanding would be promoted still further if research in the field of youth were better connected at an inter- disciplinary level. I recently reviewed another Ashgate book, Unemployed youth and social exclusion in Europe, edited by Weil, Wildermeersch and Jansen (2005). The overlap between the two volumes in the questions being addressed is considerable, yet the bodies of literature and research on which the authors build have surprising gaps, omissions and 'blind spots'. This is symptomatic of deeper disconnections in youth research that will have to be overcome if the reconceptualization of youth to which most aspire is to be achieved.

Karen Evans, Institute of Education, University of London, UK

(C) 2007, Karen Evans

\title{
Liberty and learning: Milton Friedman's voucher idea at fifty
}

Robert C Enlow and Lenore T. Ealy, 2006

Washington, DC, Cato Institute

EII.95 (pbk), I70 pp.

ISBN I-9308-6586-4

Half a century ago, in a volume addressed mainly to economists, Milton Friedman dissected The role of Government in education (Friedman, 1955). He distinguished three major roles that Government in the US was performing: legislating compulsory schooling, financing schooling and administering schools. Friedman's argument was that these were different tasks, and the rationale for Government involvement was different in each case. At that time Friedman accepted that there were dangers of market failure in education so there might be a role for Government in maintaining standards and in providing finance for children from less affluent families but he saw no reason at all for the public sector to have a near monopoly in running schools. Hence the idea of vouchers was born. Schools should be private institutions in a competitive market, with a minimum amount of quality regulation, and families with children of school age should receive vouchers, which could be 
spent at any school the parents chose. In the past half century the voucher idea in various forms has flourished in the undergrowth of economic writing about educational provision and has occasionally become a topic of interest to education policy analysts, but has rarely been taken very seriously by policy makers in Europe or North America. Milton Friedman returned to the topic himself from time to time, most comprehensively in the 1980 book Freedom to choose and briefly in a prologue and an epilogue to the present volume. It is clear that his views hardened throughout the half century and by the beginning of the twenty-first century he considered that US education at least, would be more effective and provided more efficiently if there was virtually no role for the state.

Friedman died in 2006 and this volume from the Cato Institute is in effect a festschrift celebrating his contribution to the economics of education policy. The Institute's name recalls Cato's letters, a series of libertarian pamphlets that helped lay the philosophical foundations of the early US democracy. According to its web site the Cato Institute seeks to "broaden the parameters of public policy debate to allow consideration of the traditional American principles of limited Government, individual liberty, free markets and peace'. All the contributors to Liberty and learning, except James Tooley from the University of Newcastle, are academic economists, lawyers and policy analysts from the US and it would not be misleading to describe them as being broadly of a neo-con persuasion. The articles are aimed at educational policy-makers and the media rather than the academic community. However, there is some food for thought by education leaders in Europe once they have overcome their apoplexy at the wilder rants of one or two of the authors.

The philosophical basis of Friedman's scheme is the reverse of Tawney's oft quoted dictum that what good parents want for their children a good state should provide for all its children. The underlying belief is that individual parents know better than public bodies what schools are best for their own children and that the state should interfere as little as possible. Schools should be financed and run in broadly the same way as universities in the UK, market-oriented autonomous institutions, determining, very largely, their own curricula and free to charge tuition fees: with any money received from the state being channelled through the students they recruit. This idea has been broadened from Freidman's originally rather modest ideas of vouchers as bursaries to a wide spectrum of possible policies. These range from the state retaining considerable control of quality and no possibility of individuals supplementing the money value of their vouchers to purchase a better or more luxurious education, to fully privatized schemes in which all primary and secondary education is privately provided and financed. The authors in this volume cover the whole range, from the incremental evolution in Friedmanesque directions advocated by Hanushek to Tooley's strongly expressed belief that one way of helping poor developing countries overcome their educational weaknesses is to move as rapidly as possible towards full-scale privatization.

The empirical basis of much of the writing is the acknowledged poor quality of much public education in the US. To an English reader of a certain age there is a tang of the Black Papers of the 1960s and 1970s. Empirical evidence is bandied about rather loosely but there is sufficient accumulation of (albeit cherry picked) official reports and serious research studies to make it clear that there are very serious problems and that, despite very large public funding and many experiments in social engineering, the problem has got worse not better. Much is made of the evidence that children in private schools usually 
perform better than those in state schools, though few of the authors consider possible reasons, other than that the market forces schools to be efficient and effective. Merrifield, in his contribution is blunt about it; he says in effect that everything else has failed so the marketeers should be given a chance to prove themselves.

Equality does not rate highly in the authors' scale of values, though some recognize that a few parents might not be able to carry the responsibilities they would bear. It is suggested that they might be treated as casualties and be given the kind of support that social workers provide when other aspects of life breakdown. In general the implicitly, and sometimes explicitly, expressed view is that this would be a small price to pay for an education that would be more effective and more efficient. Faith schools cause a few of the authors to have some concerns about social cohesion, but like inequality this is brushed aside as a minor issue which not many parents would take up. One interesting claim by Greene is that if faith schools were encouraged rather than discouraged many more would spring up and competition would erode any possible divisive effects.

Liberty and learning is a political tract addressed mainly to policy-makers in the US. But educationists this side of the Atlantic should not ignore it. The ideas about education, particularly on the rights of parents to have the last word in school choice, are influential in current Government policies. In addition, at a time when compulsory education or training to the age of 18 is being officially proposed, the claim that compulsory education does little to enhance the quantity or quality of education at any age needs at least to be looked at. Having experienced the almost complete marketization of higher education in the last two decades, both supporters and opponents of further privatization of schools in the UK would do well to acquaint themselves with the underlying ethical and economic arguments and ways in which the empirical evidence is being used.

\section{References}

Friedman, M. (1955) The role of Government in education, in: R. A. Solo (Ed.) Economics and the public interest (Piscataway, Rutgers University Press).

Friedman, M. \& Friedman, R. (1980) Free to choose (Harmondsworth, Penguin).

Gareth Williams, Institute of Education, University of London, UK

(C) 2007, Gareth Williams 